\title{
ALGO MÁS SOBRE EL MISTERIOSO GRUPO ETNICO DE LA PATAGONIA CENTRAL ANDINA
}

MATEO MARTINIC B.

\section{RESUMEN}

En el artículo se replantea la hipótesis de vigencia pre y protohistórica de una etnia diferente de cazadores-recolectores, los téushenkenk, en el distrito subandino oriental central de la Patagonia, aproximadamente entre los grados $44^{\circ}$ y $48^{\circ} \mathrm{S}$, sobre la base de la consideración de noticias y antecedentes aportados por la mitología y la tradición indígenas, y por la arqueología en especial la referida a los hallazgos más recientes en yacimientos del sector del ecotono estepa/bosque.

PALABRAS CLAVE: Patagonia andina, poblamiento humano, téushenkenk.

\section{MORE ABOUT THE MISTERIOUS ETHNIC GROUP OF CENTRAL ANDEAN PATAGONIA}

\begin{abstract}
The hypothesis of the prehistoric and protohistoric existence of a different hunter-gatherer group, the téushenkenk, is presented. According with the native traditions, mythology and recent archaeological research at the steppe/forest ecotone, the habitat of the teushenkenk was located on central-eastern subandean Patagonia, approximately between $44^{\circ}$ and $48^{\circ}$ South.

KEY WORD: Andinian Patagonia, human settlement, Teushenkenk

\section{INTRODUCCION}

Desde que hace más de seis décadas Federico Escalada hiciera las primeras aproximaciones en torno al por él dominado "Complejo Tehuelche" basado en las noticias recogidas entre los últimos aborígenes de la zona patagónica central que conociera en el transcurso de su trabajo profesional

en Comodoro Rivadavia -principalmente de boca de su excelente informante Agustina Quilchamal-, pareció quedar en claro que además de los grupos étnicos reconocidos tradicionalmente como habitantes originarios para el territorio patagónico oriental situado entre la parte septentrional de la cuenca del río Chubut y el estrecho de Magallanes: Guenena Kene (Gennaken) en los sectores norte y

Profesor Titular y Emérito, investigador Centro de Estudios del Hombre Austral, Instituto de la Patagonia, Universidad de Magallanes.mateo.martinic@umag.cl.
\end{abstract}


central, sector este último que compartían con los Aónikenk, cuyo territorio principal se situaba en la parte meridional desde el río Santa Cruz hasta el estrecho de Magallanes, había un tercer grupo étnico, el de los Téushenkenk (o Chehuachekenk) cuyo territorio propio se habría situado en la región subandina de la Patagonia, aproximadamente entre las latitudes $44^{\circ}$ y $48^{\circ} \mathrm{S}$, un tanto misterioso por la imprecisión y la vaguedad de las referencias brindadas sobre el mismo por los informantes indígenas.

Con posterioridad el etnólogo Rodolfo Casamiquela se ocupó largamente de la materia e hizo su propia clasificación distinguiendo entre los Tehuelches septentrionales boreales y los septentrionales australes (entre los que los incluyó a los guenena kene) y los tehuelches meridionales boreales y tehuelche meridionales australes, a los que reconoció como los propiamente áonikenk. Para este autor los guenena kene y los téushenkenk habrían sido un grupo único habitante de la precordillera chubutense, en tanto que los mecharnúekenk (gente de la resina del molle), hablantes de la lengua téushen (tewsen), habrian radicado igualmente en la precordillera al sur de aquéllos. Reconoció, sin embargo, que el asunto de la identificación étnica patagónica era un asunto harto complejo que distaba de quedar resuelto a satisfacción, pues sólo se disponía hasta su tiempo (fines de los años de 1980) de las informaciones que eran el fruto exclusivo de la memoria indígena tardía fundada en la tradición oral, y era necesario conseguir otros antecedentes complementarios procedentes de la arqueología que permitiera fundar mejor la suposición qué se hacía o la percepción que se tenía acerca de la vigencia histórica de un grupo humano que habitaba el territorio marginal en la región preandina oriental de la Patagonia.

Más tarde contribuimos personalmente con una referencia específica novedosa recogida de la tradición indígena (Martinic, 2000) y desde una época más reciente Tegai Roberts y Marcelo Gavirati han agregado otra interesante noticia del género (Roberts \& Gavirati, 2008), cuya clara relación con el dato precedente resulta sugerente y congruente y permite formular algunas consideraciones respecto de lo que pudo ser aquel poco conocido grupo étnico subandino oriental y con ello ofrecer una mejor aproximación a su presunta identidad.

Interesa así hacer una comparación entre estas dos noticias históricas tanto respecto de su contenido y su coherencia, como de su congruencia con la tradición tardía, valorándola especialmente a la luz de las informaciones suministradas por la arqueología desde 1990 hasta el presente.

\section{LA INFORMACIÓN ENTREGADA POR SANTOS CENTURION EN 1845}

Santos Centurión era un "criollo aindiado" como se conocía por la época (siglo XIX) a los civilizados que voluntariamente residian entre los aborígenes. Arribado a la Patagonia en el curso de los años de 1820 conoció a los aónikenk, se casó con una india, adoptó sus costumbres, aprendió su lengua y se enteró de sus tradiciones y mitos. Ello le hizo ser un interlocutor e intérprete fiable para los foráneos que deseaban establecer alguna relación con los indígenas o simplemente informarse sobre ellos. Fue especialmente estimado por los gobernadores de la Colonia de Magallanes como un intermediario de confianza para sus tratos con los naturales.

He aquí la parte fundamental de su relación sobre la vida indígena recogida hacia 1845 por James Dunne, secretario de la Gobernación de la Colonia: [...] Según Centurión que entre el río Negro y el de Sta. Cruz, por el camino interior que es por donde viajan los indios, hai dos lugares en donde se encuentran bastantes casas de piedras pintadas de varios colores, $y$ las cuales están habitadas por una raza que según la detallan los Patagones tienen mucha semejanza con los orangutanes: dichos sitios [no] están sobre el mismo camino si no así á [hacia] los Andes. Talla pequeña, cuerpo belloso y un palo ó báculo siempre en la mano. Se cubren con un manto corto de cuero de guanaco del mismo modo que los de la tierra del fuego. Los Patagones les llaman Chelep. La mayor parte de estas indiadas han visitado esos lugares y han estado en las mismas casas; pero nunca han podido tomar uno de sus habitantes á pesar de que los han divisado y corrido muy de cerca y aun recibiendo algunas piedras tiradas por ellos: lo que ha dado ocasión para que los tengan por brujos, y no se llegan á las cuebas, pues no deben ser otra cosa, 
[ilegible] en gran número. Debe advertirse que los Patagones solo cuando van á río Negro, cosa que no sucede con frecuencia, es cuando los chelep los divisan llegar, pues siempre lo han hecho de dia, huyen y se les pierden entre los montes abandonando las habitaciones en las cuales se encuentran huesos y cueros de guanacos y que algunas veces que han solido dormir cerca de tales casas les han robado y muerto algunos caballos. Centurión agrega que él no ha ido por esos campos, y por consiguiente que no ha tenido ocasión de conocer la verdad de todo esto; pero que tiene por cierto lo que lo que los Indios refieren en virtud de que su mujer los ha visto siendo joven en una ocasión que fue al rio Negro, y la cual tuvo una aventura hallándose en aquellas habitaciones solamente acompañada de una hermana mayor, mientras todos los demás que con ella iba se habian ido al campo lejos.

Los indios en general, revisten los cuentos de los chelep con algo de fabuloso y a sus niños les meten miedo con ellos; pero puede colegirse que los tales chelep son alguna tribu de la raza tehuelche refugiada en esas soledades muchos años ha y por esto sus compatriotas no tienen noticias de ellos ${ }^{1}$.

\section{LA VERSION RECOGIDA \\ POR LLWYD AP IWAN EN 1894}

Llwyd ap Iwan era un miembro distinguido de la comunidad galesa que había iniciado en 1865 la ocupación colonizadora del valle inferior del río Chubut bajo los auspicios del gobierno argentino. Hijo de Michael D. Jones e ingeniero de profesión inició sus actividades al promediar los años de 1880 en las labores propias de su especialidad, pero asimismo se interesó tempranamente por el conocimiento del vasto territorio que abarcaba la cuenca hidrográfica de aquel curso principal y de sus tributarios hasta sus orígenes en la precordillera patagónica oriental; fue así que participó en varias expediciones exploratorias que permitieron obtener paulatinamente el mejor conocimiento del territorio occidental teniendo

1 M. Martinic, Informaciones etnográficas extraídas del diario inédito de Santiago Dunnes, Secretario de la Gobernación de en miras la explotación de sus recursos naturales, en especial los minerales. En algunas de ellas, particularmente en aquellas que se desarrollaron sobre sectores noroccidentales del territorio de Santa Cruz, Llwyd ap Iwan conoció y trató largamente al jefe aónikenk Kánkel, que dirigía una pequeña comunidad mixta de aborígenes del sur y mapuches resultante de la diáspora originada en el mundo indígena de la Patagonia tras la campaña del Desierto del Ejército Argentino entre 1879 y 1883, circunstancia que le posibilitó informarse sobre la vida de los indígenas incluyendo sus narraciones tradicionales.

En una de estas ocasiones que le permitieron pasar varios días en compañía de los aborígenes, Llwyd ap Iwan pudo recoger de su interlocutor algunas narraciones de interés, entre las que transcribimos en parte aquella registrada en su diario de viaje con fecha 17 de febrero de 1894: Durante las tardes que pasamos en compañía de Gangeel [Kánkel] nos contó varias interesantes narraciones que son tradicionales entre su gente. Por ejemplo, supuestamente, los avestruces vinieron originalmente de Genua al norte del lugar donde nosotros estábamos y los guanacos de Pacheekaik, un campamento al sudeste del lago Buenos Aires. A corta distancia al norte de Pacheekaik había un volcán dormido, llamado Ashpaik. En cierta oportunidad el buen dios ordenó a sus ancestros que hicieran algo, pero ellos fueron negligentes en cumplir su mandamiento y todos sus caballos entraron a la tierra por el cráter de este volcán y desde entonces el cráneo petrificado de un caballo guarda el lugar. Cuando llamé su atención sobre los sepulcros o montones de piedras que encontramos en todos lados, aún lejos, dentro de los Andes, donde los tehuelches nunca entran, excepto cuando ocasionalmente unos pocos cazadores van detrás de vacas salvajes, él nos informó que éstas eran tumbas de indios de una tribu diferente a la suya, que no tenían caballos pero que vivian en las montañas; eran muy feroces y fuertes. Su padre había capturado y mantenido prisionero a uno de ellos; el Catchwalt-como

Magallanes (Anales del Instituto de la Patagonia, Serie Cs. Humanas, 28, 2000), pp. 49. Lo destacado es del autor. 
él lo llamaba-derramó tantas lágrimas que la región se inundó de lluvia, seguida por tanta nieve que estaban en peligro de ser sepultados. Liberado el Catchwalt, se fue directamente hacia las montañas murmurando en una lengua que ellos no entendían; entonces salió el sol en todo su esplendor, se derritió la nieve y sus temores cesaron ${ }^{2}$.

Casamiquela que conoció esta información y la comentó en nota al pie, identificó a Catchwalt con el personaje Táchul o Tachualt mencionado por Agustina Quilchamal, recordando al efecto sus palabras referidas al mismo relato: [...] la tierra se dio vuelta y tapó a la gente chiquita..., entendiendo que con tal expresión quería significar a los enanos o "gnomos" de Escalada.

\section{COMPARACIÓN ANALÍTICA DE AMBAS VERSIONES}

A1 leer una y otra narración salta de inmediato a la vista su parentesco identitario esencial, pues hay en una y otra elementos descriptivos que mutatis mutandi son semejantes, como puede apreciarse de la siguiente comparación de las partes pertinentes:

\section{RELATO DE CENTURIÓN}

Entre el río Negro y el de Santa Cruz por el camino interior que es por donde viajan los indios (Precordillera oriental)

\section{RELATO DE KÁNKEL}

Dentro de los Andes... donde los tehuelches nunca entran... en las montañas (Precordillera)

\begin{tabular}{|c|c|c|}
\hline $\begin{array}{c}\text { Referencia específica de } \\
\text { lugar }\end{array}$ & $\begin{array}{c}\text { Dos lugares en donde se encuentran bastantes casas } \\
\text { de piedra pintadas de varios colores (abrigos o } \\
\text { cuevas) (Sitios de arte parietal ubicados en la zona } \\
\text { precordillerana) }\end{array}$ & $\begin{array}{l}\text { Sepulcros o montones de piedra: tumbas } \\
\text { de indios diferente a la suya }\end{array}$ \\
\hline Tipo humano & $\begin{array}{c}\text { Raza "que tiene mucha semejanza con los } \\
\text { orangutanes" Talla pequeña, cuerpo velloso y } \\
\text { un palo o báculo siempre en la mano. No tenían } \\
\text { caballos. }\end{array}$ & $\begin{array}{l}\text { Muy feroces y fuertes no tenía caballos } \\
\text { hablaban una legua diferente. Gente } \\
\text { chiquita (Agustina Quilchamal) }\end{array}$ \\
\hline Denominación & Chélep & $\begin{array}{c}\text { Catchwalt o Táchual (Casamiquela sensu } \\
\text { Quilchamal). }\end{array}$ \\
\hline
\end{tabular}

Visto lo expuesto, nos parece claro que nos hallamos ante dos versiones que corresponden a una misma tradición legendaria que pudo ser compartida por grupos de una semejante etnia, que para el caso era la aónikenk, o de diferentes etnias en el supuesto de que Kánkel no hubiera sido propiamente un aónikenk sino un "tehuelche meridional boreal" o un "tehuelche septentrional austral" que, de cualquier modo poseían un acervo mítico común remontable a un tiempo muy remoto y que daba cuenta de la existencia de un grupo humano diferente en su tipo físico, su lengua y sus costumbres y que habitaba en la región preandina oriental de la Patagonia, distinto por tanto al que caracterizaba al propio de los informantes. En esta posibilidad cabe indagar y

2 Tegai Roberts y Marcelo Gavirati, Diarios del explorador Llwyd ap Iwan. (Patagonia Sur Libros-La Bitácora hacer consideraciones sobre los fundamentos que puedan dar verosimilitud a la hipótesis de una tal existencia étnica diferenciada.

\section{EL APORTE DE LAS INVESTIGACIONES ARQUEOLOGICAS}

Cuando Casamiquela reflexionaba en 1988 sobre la materia expresando que sería interesante encontrar una tumba tehuelche en la zona geográfica de interés y aun excavarla en procura de información, probablemente desconocía que la investigación arqueológica ya había hecho las primeras aportaciones sugerentes para adelantar en el aspecto que nos ocupa. En efecto, Francisco Mena había dado a conocer años antes sus trabajos

Editores, Buenos Aires 2008), pp. 92-93. Lo destacado es nuestro. 
referidos al sitio Cueva de Las Guanacas (valle inferior del río Ibáñez, Región de Aysén) en que daba cuenta de una serie de ocupaciones de aleros y cuevas con antigüedad datada entre 5.400 años antes del presente y el siglo XVI, que incluían varios estratos culturales, uno de los cuales se asociaba con pinturas parietales (Mena, 1983). Se trató entonces de una primera información referida a la zona precordillerana oriental de la Patagonia central.

Pocos años después, en 1986, el mismo arqueólogo realizó la excavación del sitio Alero Entrada Baker, situado aproximadamente un grado geográfico al sur del anterior, cuya característica fisionómica -abrigo rocoso con arte parietal y huellas culturales de una ocupación históricamente reciente aunque anterior al dominio del caballo por los cazadores patagónicos- lo relacionaban con el Alero Las Guanacas en suelo chileno y permitían asimismo hacer una comparación entre sus hallazgos con aquellos propios del relativamente vecino sitio Cerro de los Indios en suelo argentino (Mena \& Jackson, 1991), aunque sin que la información disponible hasta entonces fuera suficientemente esclarecedora.

Un adelanto ciertamente importante se tuvo en tal sentido una vez que el mismo Mena $y$ otros dieron a conocer los resultados obtenidos con la excavación del sitio Cueva Baño Nuevo 1 situado más al norte en territorio chileno próximo a la frontera internacional $\left(45^{\circ} 17^{-} \mathrm{S} / 71^{\circ} 30^{\circ} 0\right)$. En síntesis, otra vez se trataba de una ocupación en cueva, con dos componentes culturales, uno temprano que se remonta al décimo milenio antes del presente y otro tardío, ubicado entre 3.000 y 1.000 años igualmente antes del presente. Lo más notable de este trabajo fue el hallazgo de restos humanos en el primero de ellos -los más antiguos hasta ahora conocidos- correspondientes a individuos inhumados por los ocupantes de la cueva, circunstancias que brindó también noticias sobre su funebria. Así, por vez primera la ciencia disponía, como dispone, de una posibilidad de estudio paleoantropológico para conocer las características físicas y otras variables sobre la gente que hace unos 10.000 años habría conformado el primer contingente poblador en la región precordillerana oriental (Mena et al. 2000).

Pero si de avanzar en el conocimiento del poblamiento antiguo de ese distrito subandino se trataba, en el contexto que interesa, esto se logró con la serie de trabajos arqueológicos desarrollados en la zona oriental de Aysén en el trascurso de la primera década del siglo XXI y ampliados hasta el inicio de la segunda por los arqueólogos Omar Reyes, Cesar Méndez, Hector Velásquez, Valentina Trejo y otros, que se han concentrado en la zona de transición estepa/bosque de la precordillera oriental (valles medio y superior del río Cisnes, $44^{\circ}$ $\mathrm{S}$, región de Aysén). Con ellos, sitios Aleros Las Quemas, Winchester 1, Appeleg 1, El Chueco 1, Alero del Toro y Chenque Pampa El Frío entre otros, se ha conseguido tener un acervo riquísimo, sin embargo de hallarse en fase de estudio particularizado, que brinda la certidumbre de una presencia humana recurrente desde el Holoceno temprano hasta el siglo XIX en la zona transicional estepa/bosque y con sugerentes contactos con pueblos de ultracordillera, con sus rasgos culturales caracterizadores: habitación en cuevas o aleros, arte rupestre, utilería y alimentación, funebria (Reyes, 2002; Méndez \& Reyes, 2006; Reyes et al. 2007 a y b, 2009; Méndez et al. 2010; Reyes \& Méndez, 2010, 2011).

En buenas cuentas, con sólo lo adelantado a contar de 2002 y hasta el presente en lo referido al suelo chileno, más la información acumulada sobre la correspondiente al argentino inmediato, la arqueología está permitiendo dilucidar la materia que nos ocupa. Si en ello pudo pensar Rodolfo Casamiquela, nunca imaginó cuán rico y valioso habría de ser el acervo informativo suministrado por la arqueología para entender mejor el arcano poblacional de la precordillera patagónica oriental.

\section{SÍNTESIS DE LO CONOCIDO SOBRE EL MISTERIOSO GRUPO ÉTNICO SUBANDINO ORIENTAL}

Las noticias entregadas a Escalada por Agustina Quilchamal y las obtenidas del diario de viaje de Lwyd ap Iwan han sido, según parece, los primeros indicios conocidos que permitieron postular la vigencia de un poblamiento étnicamente diferenciado en la extensa franja territorial que incluye el sector transicional estepa/bosque de la Patagonia subandina oriental comprendida en general entre las latitudes $44^{\circ}$ y $48^{\circ} \mathrm{S}$. A ello hubo 


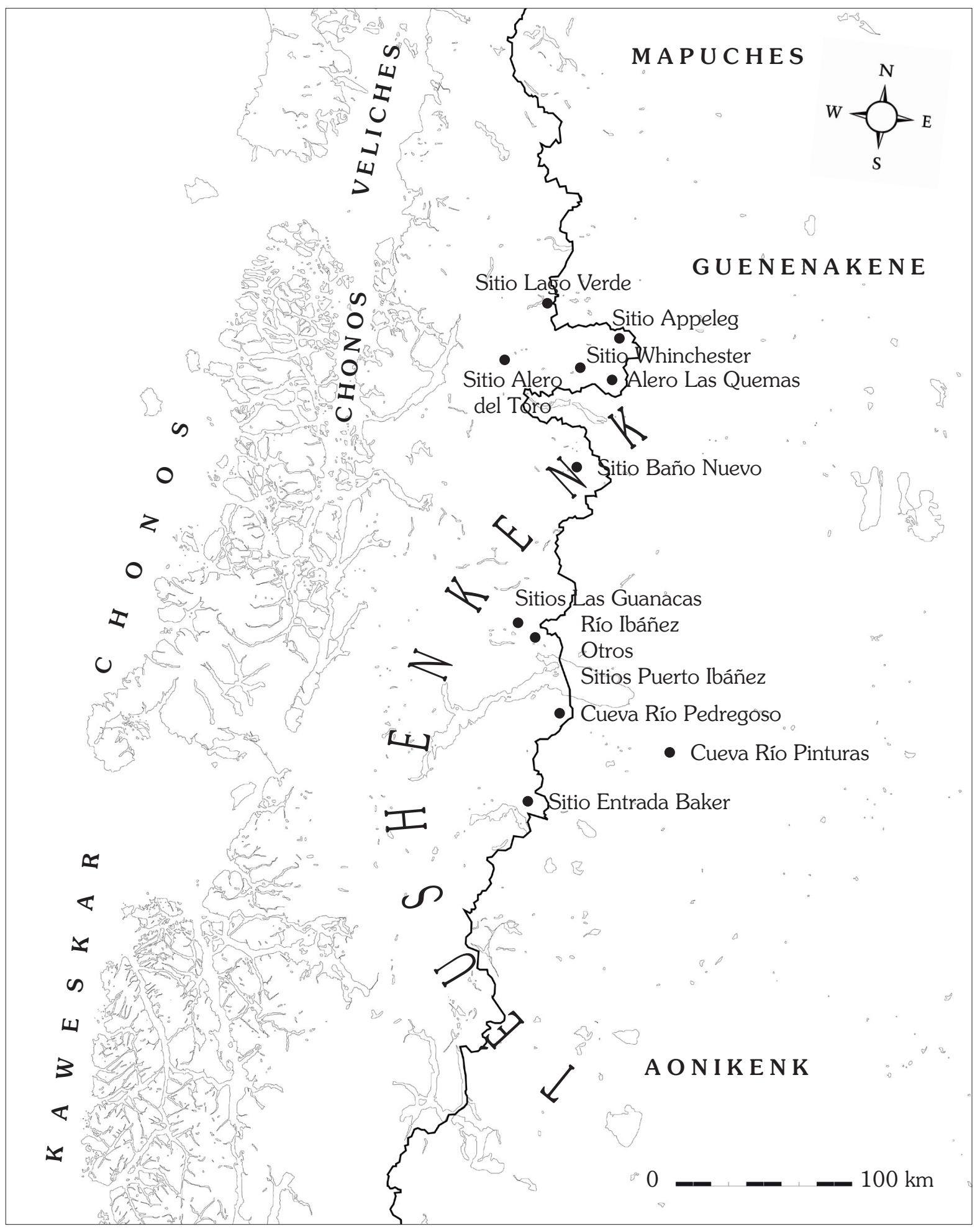

Fig. 1. Localización del posible grupo étnico Téushenkenk en la Patagonia Central Andina 
de sumarse posteriormente por nuestro intermedio el dato brindado por Centurión en $1845 \mathrm{y}$, sucesivamente, los resultados publicados referidos a las primeras investigaciones arqueológicas hasta el 2002. Con esos antecedentes a la vista, personalmente planteamos como hipótesis que en la zona geográfica de que se trata hubo una secuencia poblacional de larga vigencia que habitó en abrigos rocosos y cuevas, que practicó la pintura parietal, que tuvo modalidades propias de inhumación de sus muertos y que debió incursionar tierra adentro hasta las montañas andinas $y$, eventualmente, atravesarlas en plan de exploración de sus recursos alimentarios brindando a los cazadores de la banda oriental la posibilidad de contacto con sus congéneres de la banda occidental (Martinic, 2005).

Agregamos entonces que los desplazamientos nomádicos habituales entre diferentes campamentos-base y las excursiones realizadas a partir de los mismos a lo largo del tiempo, generación tras generación, debieron dar a esos ayseninos primitivos un buen grado de conocimiento acerca de su entorno en lo tocante a recursos para la vida y aun para ciertas prácticas sociales. Así, lentamente hubo de ir cobrando forma una suerte de identificación entre los cazadores-recolectores y el territorio en que desarrollaban su vida nomádica, en un ir y venir que quizá raramente hubo de ultrapasar una especie de límites consuetudinarios. Pensamos así que el territorio preferente, si no exclusivo de estos hombres del Tardío o aun de sus antecesores pudo abarcar un espacio geográfico amplio de entre tres y cuatro centenares de kilómetros de norte a sur, desde el lago Verde, los bosques del Cisnes y pampas de Ñirehuao a las fuentes meridionales del río Deseado, y de oeste a este desde el monte siempreverde hasta los bordes occidentales de las altiplanicies patagónicas. Si así pudo suceder con cuantos allí habitaron a lo largo de milenios, otro tanto debió ocurrir en otras zonas de la Patagonia oriental esteparia y subandina, como para explicar las individualidades étnicas históricas que definiera Federico Escalada en 1949. Lo conocido con posterioridad a 2002 y a lo que se ha hecho referencia precedente demuestra que tal

3 ¿Tehuelches y Chonos? Sobre la apertura de relaciones comunales. Cuaderno de Historia Marxista. Serie de planteamiento no era una demasía.

Abundando sobre el punto importa conocer y hacer algunas consideraciones acerca de lo postulado por el arqueólogo Felipe Bate en cuanto que es posible que haya habido algunas comunidades, en situación de aislamiento, donde la identidad étnica coincidiera con un sistema completo y cerrado de relaciones sociales de producción, reproducción, intercambios, institucionalidad, cosmovisión y sistema de valores e idioma. Pero pienso que, si las hubo, debieron ser las menos. Es mucho más probable que las comunidades, sin ser cerradas, hayan podido mantener una identidad cambiante pero distintiva a través de largos periódicos históricos aun coexistiendo con otras en las mismas regiones ${ }^{3}$.

Este supuesto pudo darse, pensamos, toda vez que el área geográfica que interesa pudo brindar los recursos para la vida humana en comunidad en su más amplio concepto, desde lo utilitario hasta lo de simple agrado espiritual, como para que allí se hubiera generado y mantenido a lo largo de mucho tiempo, milenios quizás, una existencia autónoma bien diferenciada de las de otras comunidades étnicas geográficamente próximas.

Y en esta comprensión ¿qué explicación podría darse para el distinto tipo físico de sus integrantes que los relaciona más con los aborígenes históricamente conocidos como habitantes del territorio patagónico occidental, esto es, los chonos (genéricamente "fuéguidos" según la sistematización de los antropólogos Imbelloni, Bórmida y otros de mediados del siglo XX), que con sus vecinos orientales del "complejo tehuelche"?

¿Fueron esos misteriosos pobladores de reducida talla del interior preandino un grupo marginal relictual de algunas de las corrientes migratorias que en un principio pasaron a asentarse en el vasto espacio patagónico, que pudieron tener características físicas distintas a las históricamente conocidas para los habitantes del oriente andino patagónico? ¿Qué sabemos sobre su fisionomía para fundar la aceptación de tal posibilidad?

Y si hubiera sido así, cabría plantear como hipótesis alternativa que si aquellos cazadores

América prehispánica y arqueológica. ¿Mexico? 2010, p. 397. 
recolectores cuya ocupación del territorio preandino (o de sectores del mismo) los dejó en una posición marginal, de virtual aislamiento, $y$, por consecuencia, pudo llevarlos en algún momento de su historia étnica a relacionarse con la gente de ultracordillera de modo tan intenso como para fijar un tipo humano de estatura menor que la de los cazadores recolectores propiamente esteparios y por tanto físicamente diferenciador.

El mismo Bate, valorando especialmente la información aportada por el sitio Alero El Toro, sin duda el más sugerente de cuantos se conocen, añade, igualmente como hipótesis, que... Las ocupaciones del Alero del Toro responderían al tránsito entre los territorios de comunidades de cazadores recolectores pretribales [Pre ecuestres] con modos de vida diferentes, orientadas al establecimiento de relaciones de acoplamiento y filiación ${ }^{4}$.

$Y$ en la probabilidad de que tal se diera, otra vez cabe preguntarse acerca de qué tan prolongados $e$ intensos pudieron ser esos tratos (más que meros contactos) como para que hicieran posible una mestizaje biológico caracterizado en lo que importa por la estatura individual. Pero y si tales tratos, ahora rebajados a meros contactos, con haber sido reales a la luz de la arqueología fueron únicamente de carácter esporádico ¿cómo explicar la baja estatura de los integrantes de la desconocida población subandina oriental? Misterio sobre misterio.

En la convicción de que personalmente no nos corresponde ir más allá en estas conjeturas por ser la materia a dilucidar un asunto ajeno a nuestra competencia, concluimos que en verdad queda mucho por conocer todavía para resolver tan interesante cuestión. Pero mientras la arqueología y la antropología física consigan aportar elementos significativos de certidumbre para obtener una comprensión explicativa razonable, habrá que continuar valorando la información sustancial aportada por la tradición oral de los cazadores recolectores del oriente patagónico, en cuanto la misma aún en su ropaje legendario brinda siquiera indicios de realidades que la memoria humana pudo retener porfiadamente a lo largo de siglos o milenios.

\section{FUENTES DE CONSULTA}

Alvarez, R. (2002). Reflexiones en torno a las identidades de las poblaciones canoeras situadas entre los $44^{\circ}$ y $48^{\circ}$ de latitud sur, denominadas "chonos" Anales del Instituto de la Patagonia, Serie Ciencias Humanas, 30, 79-86.

Bate, L. F. (2010). ¿Tehuelches y Chonos? Sobre la apertura de relaciones comunales. Cuaderno de Historia Marxista. Serie de América Prehispánica y Arqueología. Ciudad de México

Casamiquela, R. M. (1991). Bosquejo de una etnología de la Patagonia Austral. Waxen. Universidad Nacional de la Patagonia Austral. Río Gallegos.

Escalada, F. (1949). El Complejo Tehuelche. Instituto Superior de Estudio Patagónicos. Buenos Aires.

Martinic, M. (2000). Informaciones etnográficas extraídas del diario inédito de Santiago Dunne, Secretario de la Gobernacion de Magallanes. Anales del Instituto de la Patagonia, Serie Ciencias Humanas, 28, 45-52..

Martinic, M. (2005). De la Trapananda al Áysen. Pehuén Editores. Santiago.

Mena, F., Lucero, V., Reyes, R., Trejo, V. \& Velásquez, H. (2000). Cazadores tempranos y tardíos en la Cueva Baño Nuevo 1, margen occidental de la estepa centro patagónico (XI Región de Aisén). Anales del Instituto de la Patagonia, Serie Ciencias Humanas, 28, 173-196.

Méndez, C. \& Reyes, O (2006). Nuevos datos de la ocupación humana en la transición bosque estepa en Patagonia: Alero Las Quemas (Comuna de Lago Verde, XI Región de Aisén). Magallania, 34(1), 161-166.

Méndez, C., Reyes, O., Velásquez, H. \& Maldonado, A. (2010). Comentarios sobre una edad $14 \mathrm{C}$ en el límite Pleistoceno/Holoceno de Alero El Toro, Bosque siempre verde de Aisén. Magallania, 38(1), 281-286.

Reyes, O. (2002). Funebria indígena en el curso del valle del río Ibáñez, margen occidental de la estepa de Centro Patagonia (XI Región de Aisén). Anales del Instituto de la Patagonia, Serie Ciencias Humanas, 30, 87101.

Reyes, O., Méndez, C., Trejo, V. \& Velasquez, H. (2007a). El Chueco 1: un asentamiento multicomponente en la $\mathrm{Pa}$ tagonia Occidental Central (11.400 a 2.700 Cal. A.P. $-44^{\circ}$ S). Magallania 35(1), 107-120.

Reyes, O., Méndez, C., Trejo, V. \& Velasquez, H. (2007b). Ocupaciones humanas tardías en la transición bosque estepa: la localidad de Winchester (Curso alto del río Cisne, Región de Aisén). Magallania, 35(2), 145-150. 
Reyes, O., Méndez, C., Maldonado, A., Velásquez, H., Trejo, V., Cárdenas, M. \& Abarzúa, A. M. (2009). Uso del espacio de cazadores recolectores y paleo ambiente holoceno en el valle del río Cisnes, Región de Aysén, Chile. Magallania, 37(2), 91-108.

Reyes, O. \& Méndez, C. (2010). Precisando la cronología para la inhumación tipo chenque, valle del río Cisne (Aysén, Chile). Magallania, 38(2), 127-132.
Roberts, T. \& Gavirati, M. (Comp) (2008). Diario del Explorador Llwyd ap Iwan. Patagonia Sur Libros-La Bitácora. Buenos Aires.

Velásquez, H. (2002). En busca de aportes documentales al conocimiento de la realidad sociocultural del actual territorio oriental de Aysén en la transición del siglo XIX siglo XX. Anales del Instituto de la Patagonia, Serie Ciencias Humanas, 30, 45-64. 
